\title{
Sensitivity Analysis on Stress of the Oxygen Decompressor Shell and Optimization of the Structural Physical Parameters
}

\author{
Penghao Ren \\ College of Aerospace Engineering \\ Nanjing University of Aeronautics and Astronautics \\ Nanjing, China \\ 863741949@qq.com \\ *Fengzhi Li \\ College of Aerospace Engineering \\ Nanjing University of Aeronautics and Astronautics \\ Nanjing, China \\ helifz@nuaa.edu.cn \\ ${ }^{*}$ Corresponding author \\ Weihua Liu \\ College of Aerospace Engineering \\ Nanjing University of Aeronautics and Astronautics \\ Nanjing, China
}

\author{
Zhisheng Luo \\ Hefei Jianghang Aircraft Equipment Corporation, LTD \\ AVIC \\ Hefei, China \\ Peng Chen \\ Hefei Jianghang Aircraft Equipment Corporation, LTD \\ AVIC \\ Hefei, China \\ Rongying Xing \\ Cheng Du Aircraft Industrial (Group) Co., LTD \\ AVIC \\ Chendu, China
}

\begin{abstract}
In order to investigate the structural stress dependence on the load conditions and material parameters, reduce and optimize the design variables, an orthogonal numerical test method is presented. First of all, the oxygen decompressor stress sensitivities to pressure, inertia force, elastic modulus and Poisson's Ratio are analyzed based on the method. The results show that besides the effects of the pressure and the inertial force controlled by environmental load conditions, the effect of the elastic modulus on the stress is greatest; Then, the elastic modulus of the spring cavity, shell and screw are optimized by the optimization, and the optimal combination of elastic modulus for minimum stress is obtained. The conclusion shows that: the method used in this paper has a small amount of calculation, and can meet the requirement of the engineering design.
\end{abstract}

Keywords- Orthogonal design; Sensitivity; Oxygen decompressor; Finite Element; Optimization

\section{INTRODUCTION}

Oxygen decompressor is one of the main accessories of the oxygen adjusting part in aircraft oxygen systems. It plays decompression and stabilizing pressure role. In the oxygen supply system, pressure reducing and stabilizing performances will directly affect the working conditions of the oxygen supply system ${ }^{[1,2]}$. Shell is an important part of oxygen decompressor ${ }^{[3]}$. When the reducer is in the failure condition, the stress must meet the strength requirements. Oxygen decompressor in the failure condition, the internal pressure, elastic modulus, Poisson's ratio and inertia force will influence the shell's stress. In order to obtain the main factors affecting the shell stress, the stress sensitivity analysis needs to do. After anlyzing the sensitivity, the variables with small sensitivity can be ignored, and that with large sensitivity can be optimized. There are many kinds of structure optimization design method, such as the criterion method ${ }^{[4]}$, mathematical programming method ${ }^{[5]}$. However, these methods are used to solve design variables problem for minimizing objective function under constrained conditions. Most of all need to do iterative calculation, generally have a greater workload. And some algorithms require sensitivity calculation. For more complex problems, more grids have to be subdivided. As large amount of computer time. Therefore, the iteration optimization is often not feasible. The orthogonal design method by orthogonal table scientific arrangement and multi-factor analysis of the level of experimental, is commonly used in the experimental design ${ }^{[6 \sim 8]}$. The experimental design method is an efficient, rapid and economic. It is based on the orthogonality of the comprehensive test from selected representative points test. These representative points have a "uniform dispersion, neat features ". After analyzing the experiment results, we can find out the primary and secondary relationship between various factors and the optimal collocation conditions, which can provide powerful guidance for the performance optimization of experimental object. In order to avoid the lack of criterion method and the mathematical programming method, this paper uses the orthogonal design scheme to design the parameters, and uses the finite element program to calculate the stress of oxygen decompressor. Finally, the results of sensitivity analysis are obtained, and the main influence factor (the elastic modulus) is optimized. a result of more nodes, the calculation needs to consume a 


\section{MODEL}

Oxygen decompressor is mainly composed of spring cavity, shell, screws and other parts. The high pressure oxygen from the high pressure inlet passes into the shell, after a series of physical processes then out off from the low pressure outlet. After this process, pressure decreased. The model is shown in Fig .1 and the Fig .2 shows the mesh plots of the model (The number of nodes and elements are 276369 and 83603,respectively.)

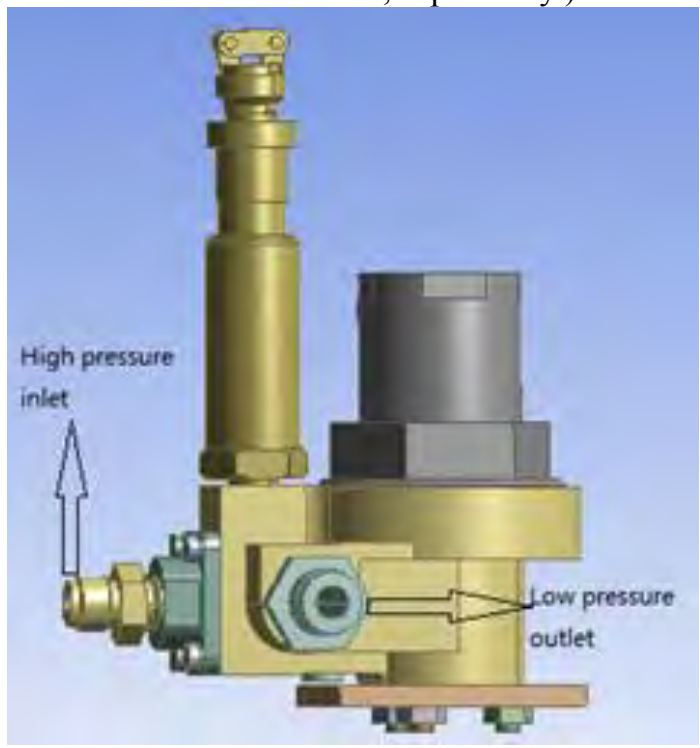

Figure 1. Structural Model

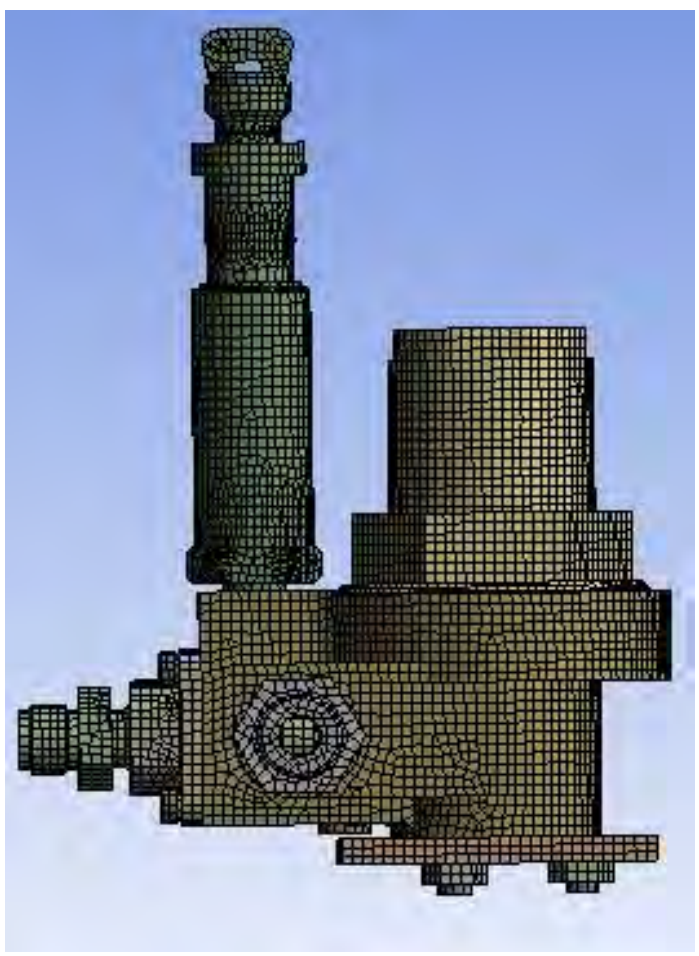

Figure 2. mesh plots

When the decompressor is in the failure condition, the internal pressure, elastic modulus, Poisson's ratio and inertia force will influence the shell's stress. The tress nephogram of decompressor and shell on the condition of pressure of $10 \mathrm{MPa}$, shell elastic modulus of $210 \mathrm{GPa}$, inertia force of $20 \mathrm{~g}$, poisson's ratio of 0.3 are shown by Fig .3 and Fig .4, respectively.

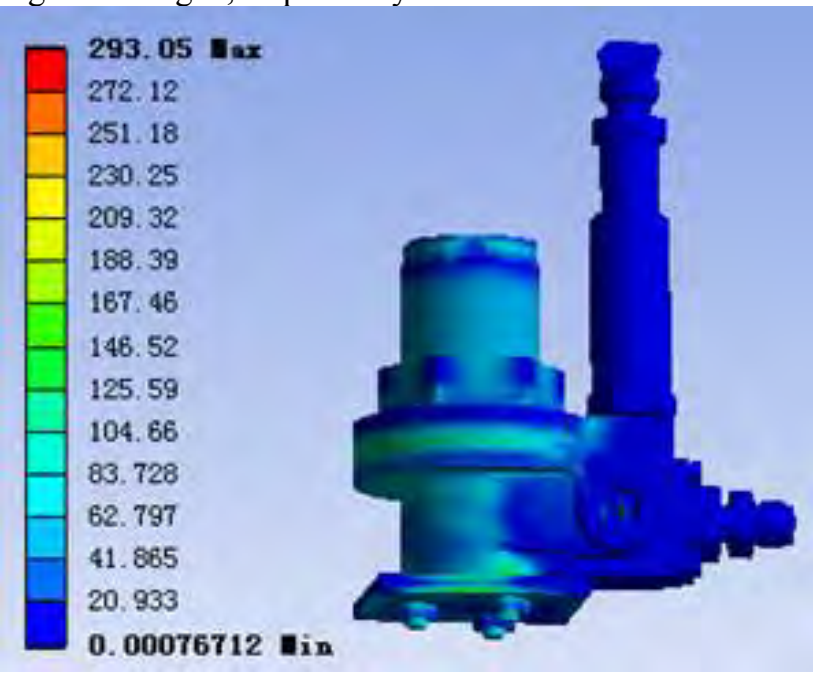

Figure 3. The tress nephogram of decompressor

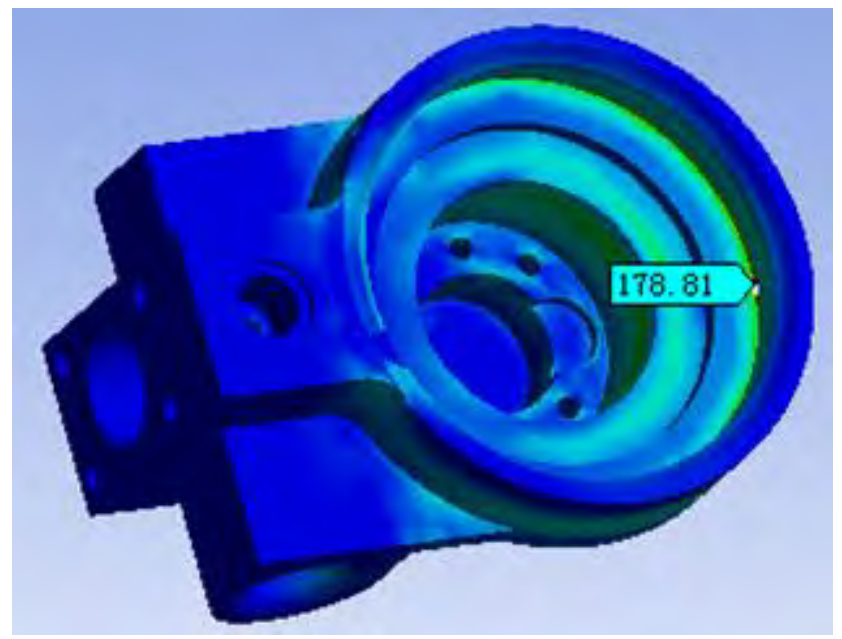

Figure 4. The tress nephogram of shell

III. THE SENSITIVITY ANALYSIS ON STRESS OF THE OXYGEN DECOMPRESSOR SHELL

We Select the factors of internal pressure, elastic modulus, Poisson's ratio and inertia force, ignore the interaction between different factors and use the orthogonal array of $\mathrm{L}_{9}\left(3^{4}\right)$ to carry out orthogonal experiment. The factors and levels are shown in Table I .

TABLE I. FACTORS AND LEVELS USED IN ORTHOGONAL DESIGN

\begin{tabular}{|l|l|l|l|l|}
\hline & $\begin{array}{c}\text { Internal } \\
\text { Pressure } \\
\text { /MPa }\end{array}$ & $\begin{array}{c}\text { Elastic } \\
\text { Modulus } \\
\text { /GPa }\end{array}$ & $\begin{array}{c}\text { Inertia } \\
\text { Force } \\
/ g\end{array}$ & $\begin{array}{c}\text { Poisson's } \\
\text { Ratio }\end{array}$ \\
\hline Level 1 & 2 & 72 & -20 & 0.30 \\
\hline Level 2 & 6 & 103 & 0 & 0.32 \\
\hline Level 3 & 10 & 210 & 20 & 0.34 \\
\hline
\end{tabular}

Since various parameters potentially affect the stress of shell, so we need to find the major influencing parameter. The orthogonal calculation table II is used to detect the major parameter for affecting the stress of shell ${ }^{[9,10]}$. 
TABLE II. ORTHOGONAL ARRAY ANALYSIS OF THE EFFECTING FACTORS ON THE SHELL STRESS

\begin{tabular}{|c|c|c|c|c|c|}
\hline & $\begin{array}{c}\text { Inertia } \\
\text { force } \\
/ \mathrm{MPa}\end{array}$ & $\begin{array}{c}\text { Elastic } \\
\text { Modulus } \\
\text { /GPa }\end{array}$ & $\begin{array}{c}\text { Inertia } \\
\text { Force } \\
\quad / g\end{array}$ & $\begin{array}{c}\text { Poisson's } \\
\text { Ratio }\end{array}$ & $\begin{array}{c}\text { Nodal } \\
\text { stress at } \\
\text { dangerous } \\
\text { location } \\
/ \text { MPa }\end{array}$ \\
\hline 1 & 2 & 72 & 20 & 0.32 & 31.75 \\
\hline 2 & 6 & 72 & -20 & 0.30 & 101.46 \\
\hline 3 & 10 & 72 & 0 & 0.34 & 164.53 \\
\hline 4 & 2 & 141 & 0 & 0.30 & 34.55 \\
\hline 5 & 6 & 141 & 20 & 0.34 & 101.67 \\
\hline 6 & 10 & 141 & -20 & 0.32 & 174.11 \\
\hline 7 & 2 & 210 & -20 & 0.34 & 35.44 \\
\hline 8 & 6 & 210 & 0 & 0.32 & 106.27 \\
\hline 9 & 10 & 210 & 20 & 0.30 & 178.81 \\
\hline $\mathbf{K}_{1}$ & 101.74 & 297.74 & 310.68 & 314.82 & \\
\hline $\mathbf{K}_{2}$ & 309.40 & 310.33 & 305.35 & 312.13 & \\
\hline $\mathbf{K}_{3}$ & 517.45 & 320.52 & 312.23 & 301.64 & \\
\hline$\overline{K 1}$ & 33.91 & 99.25 & 101.78 & 104.94 & \\
\hline$\overline{K 2}$ & 103.13 & 103.44 & 103.56 & 104.04 & \\
\hline$\overline{K 3}$ & 172.48 & 106.84 & 104.08 & 100.55 & \\
\hline $\mathbf{R}$ & 138.57 & 7.59 & 2.30 & 4.39 & \\
\hline
\end{tabular}

After calculating nine cases in Table II, we obtain the nodal stress at dangerous location, and is shown in the last column. $\mathrm{K}_{1}, \mathrm{~K}_{2}, \mathrm{~K}_{3}$ represent the sum of the nodal stress at dangerous location of the level, respectively. $\overline{K 1}$ $\overline{K 2}$ and $\overline{K 3}$ are the mean value of $\mathrm{K}_{1}, \mathrm{~K}_{2}, \mathrm{~K}_{3}$, respectively. $\mathrm{R}$ represents the range. Take the elastic modulus as an example (we select the value of elastic modulus is $210 \mathrm{GPa}$ ).

$$
\begin{gathered}
\mathrm{K}_{3}=35.44+106.27+178.81=320.52 \\
\overline{K 3}=\mathrm{K}_{3} / 3=106.84
\end{gathered}
$$

As the same method we can calculate the value of $\overline{K 2}$ and $\overline{K 1}$

So

$\mathrm{R}=\max (\overline{K 1}, \overline{K 2}, \overline{K 3})-\min (\overline{K 1}, \overline{K 2}, \overline{K 3})=7.59$.

From Table II, we know that the $\mathrm{R}$ of pressure value is largest, followed by elastic modulus. The results show that besides the pressure and the inertial force controlled by environmental load conditions, elastic modulus on the stress impact is greatest.

\section{OPTIMIZATION OF THE STRUCTURAL PHYSICAL PARAMETER}

We Select the factors of elastic modulus of the spring cavity, shell and screw, use the orthogonal array of $\mathrm{L}_{9}\left(3^{3}\right)$ to carry out orthogonal experiment ${ }^{[9,10]}$ (we select the value of internal pressure is $10 \mathrm{MPa}$, the value of Poisson's ratio is 0.3 and the value of inertia force is $20 \mathrm{~g}$ ).

TABLE III. ORTHOGONAL ARRAY ANALYSIS OF THE STRUCTURAL

\begin{tabular}{|c|c|c|c|c|}
\hline & $\begin{array}{c}\text { Spring } \\
\text { Cavity's } \\
\text { Elastic } \\
\text { Modulus } \\
\text { /GPa }\end{array}$ & $\begin{array}{c}\text { Shell's } \\
\text { Elastic } \\
\text { Modulus } \\
\text { /GPa }\end{array}$ & $\begin{array}{c}\text { Screw's } \\
\text { Elastic } \\
\text { Modulus } \\
\text { /GPa }\end{array}$ & $\begin{array}{c}\text { Nodal Stress } \\
\text { at Dangerous } \\
\text { Location } \\
\text { /MPa }\end{array}$ \\
\hline 1 & 72 & 72 & 72 & 178.66 \\
\hline 2 & 141 & 72 & 141 & 171.02 \\
\hline 3 & 210 & 72 & 210 & 167.10 \\
\hline 4 & 72 & 141 & 141 & 185.02 \\
\hline 5 & 141 & 141 & 210 & 178.38 \\
\hline 6 & 210 & 141 & 72 & 173.94 \\
\hline 7 & 72 & 210 & 210 & 187.86 \\
\hline 8 & 141 & 210 & 72 & 182.23 \\
\hline 9 & 210 & 210 & 141 & 178.27 \\
\hline $\mathbf{K}_{1}$ & 551.54 & 516.78 & 534.83 & \\
\hline $\mathbf{K}_{2}$ & 531.63 & 537.34 & 534.31 & \\
\hline $\mathbf{K}_{3}$ & 519.31 & 548.36 & 533.29 & \\
\hline $\mathbf{R}$ & 32.23 & 31.58 & 1.54 & \\
\hline
\end{tabular}
PHYSICAL PARAMETER OPTIMIZATION

From Table III we can know that The optimal combination of the elastic modulus for minimum stress is $210 \mathrm{GPa}, 72 \mathrm{GPa}$ and $210 \mathrm{GPa}$ for spring cavity, shell and screw, respectively. The tress nephogram of decompressor and shell on the condition are shown in Fig .5 and Fig .6, respectively. 


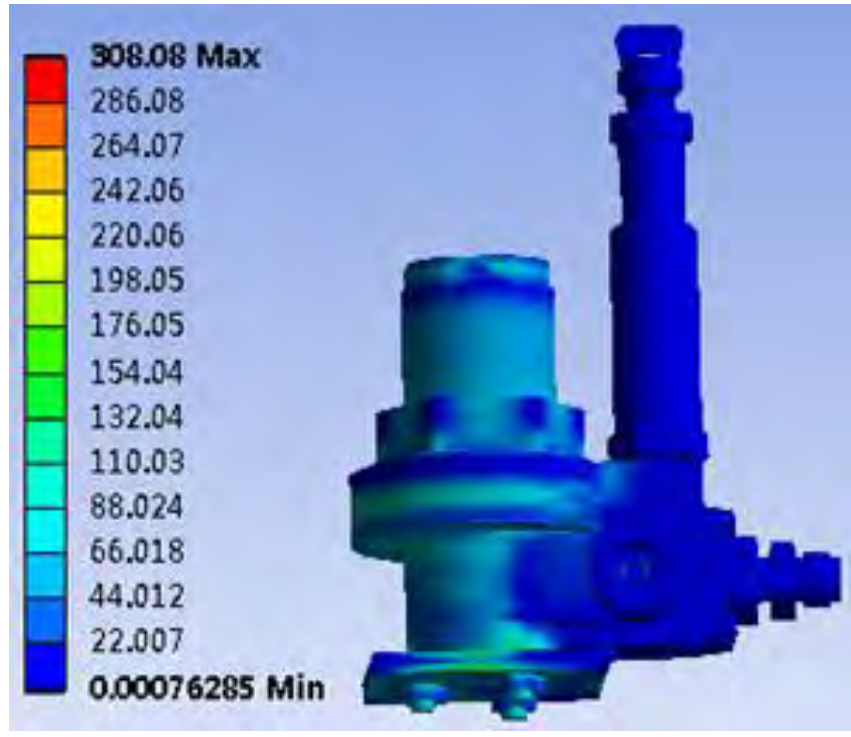

Figure 5. The stress nephogram of decompressor

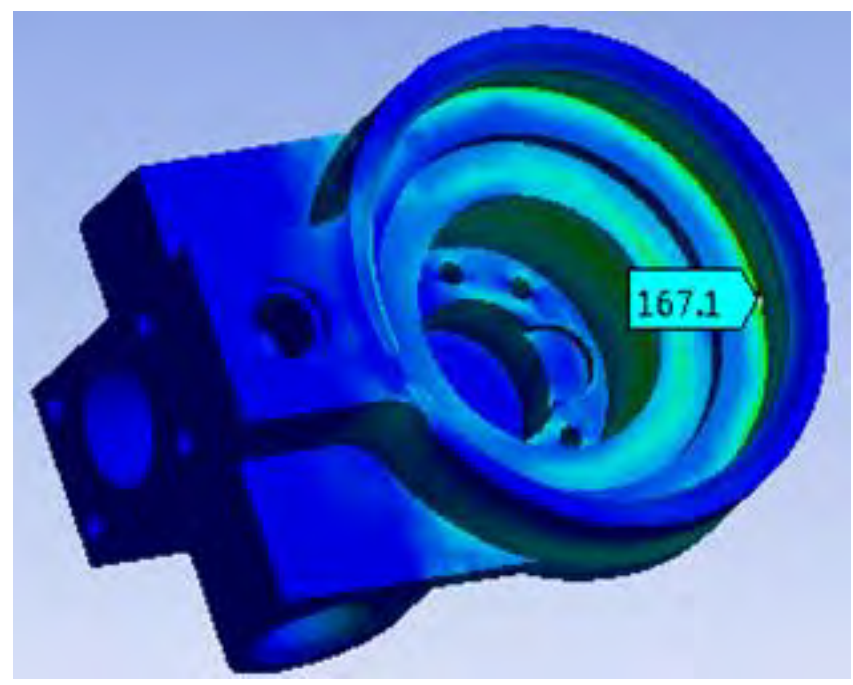

Figure 6. The stress nephogram of shell

\section{CONCLUSION}

Based on the orthogonal numerical test method, this paper investigates stress sensitivity and effect of combination of material physical parameters on stress. Conclusion shows that besides the effect of the pressure and the inertial force controlled by environmental load conditions, the effect of the elastic modulus on the stress is greatest. The optimal combination of the elastic modulus for minimum stress is $210 \mathrm{GPa}, 72 \mathrm{GPa}$ and $210 \mathrm{GPa}$ for spring cavity, the shell and the screw, respectively. Also, we can say that the method used in this paper has a small amount of calculation, and can meet the requirement of the engineering design.

\section{ACKNOWLEDGMENT}

This work has supported by the Fundamental Research Founds for the Central Universities (No. NS2013007).

\section{REFERENCES}

[1] Xiao Hua-jun. Physiology of aviation oxygen protective equipmen [M]. Beijing Military Medicine Science Press, 2005,374 379 (in Chinese)

[2] Yu Zhong-jun, Zhao Jing-quan. Simulation on Pressure Regulator Characteristic [J]. Beijing: Journal of Beijing University of Aeronautics and Astronautics, 2009, 35(11): 1379 1383

[3] Yu Xiao, Sun Bing, Lin Gui-ping et al.. Simulation and Analysis of Reverse-type Pressure Regulator. Beijing: Journal of Beijing: Computer Simulation,2009, 26 (11): 89 93

[4] Zhang Zhi-fei, Ni Xin-shuai, Xu Zhong-ming et al..Topologic Optimization of A Free Damping Material Based on Optima Criteria Method[J]. Chongqing: Journal of vibration and shock, 2013, 32 (14): 98 102 (in Chinese)

[5] Wu Bin, Research on Multilayer Optimization Design of Aircraft Wing Structure Based on Mathematical Programming Method [J]. Shenyang: Aircraft Design, 2012, 32 (2): 15 22 (in Chinese)

[6] Writing group of orthogonal design. Orthogonal Design Method and its Application [M]. Nangchang: Jiangxi People's Publishing House, 1979, 1 30

[7] Department of Mathematics and Mechanics, Peking University. Orthogonal Design-An Arrangement of Multi-Factor test Mathematical Methods [M]. Beijing: People's Education Press, 1977.16 24

[8] An Cheng-hao, Zhang De-qi, Mao Jia. Optimization Design Coal Mine Tunnel Bolt Support Based on Orthogonal Experimental Method and ANSYS [J]. Safety in Coal Mines. 2013,44 (8): 36 38

[9] Jiang Tong-chuan. Orthogonal Experiment Design [M]. Jinan: Shandong Science and Technology Press, 1985. 28 36

[10] Hao La-di, Yu Hua-dong. On Use of Orthogonal Experimental Design [J]. ACTA EDITOLOGICA, 2005, 17 (5): 334 335 